\title{
Column-integrated aerosol microphysical properties from AERONET Sun photometer over southwestern Spain
}

\author{
N. Prats ${ }^{1, *}$, V. E. Cachorro ${ }^{1}$, A. Berjón ${ }^{2}$, C. Toledano ${ }^{1}$, and A. M. De Frutos ${ }^{1}$ \\ ${ }^{1}$ Atmopheric Optics Group GOA-UVA, University of Valladolid, Prado de la Magdalena s/n, 47071, Valladolid, Spain \\ ${ }^{2}$ Izaña Atmospheric Research Center (CIAI). Meteorological State Agency of Spain (AEMET), Sta. Cruz de Tenerife, Spain \\ "now at: Grupo de Predicción y Vigilancia - Delegación Territorial Canarias, Meteorological State Agency of Spain \\ (AEMET), Las Palmas de Gran Canaria, Spain
}

Received: 14 April 2011 - Published in Atmos. Chem. Phys. Discuss.: 28 June 2011

Revised: 30 November 2011 - Accepted: 1 December 2011 - Published: 15 December 2011

\begin{abstract}
The aim of the present work is to carry out a detailed analysis of columnar microphysical properties obtained from Cimel sun-photometer measurements in the Southwest of Spain within the frame of the Aerosol Robotic Network (AERONET) - Iberian Network for aerosol measurements (RIMA). AERONET level 2 inversion products are analysed, in particular the particle size distribution together with their associated microphysical parameters for both fine and coarse modes: volume concentration, effective radius and the fine mode volume fraction. This work complements previous works based on aerosol optical depth (AOD) and the Ångström exponent (AE) for a global characterization of atmospheric aerosol in this area of southwestern Spain.
\end{abstract}

The analysed dataset spans between February 2000 and October 2008. Time series and statistical analysis has been carried out for these parameters in order to assess their typical values and seasonality together with their relationships with the AOD and AE. Mean values of volume particle concentration are $0.06 \pm 0.07 \mu \mathrm{m}^{3} \mu \mathrm{m}^{-2}$ for total, $0.019 \pm 0.015 \mu \mathrm{m}^{3} \mu \mathrm{m}^{-2}$ for fine and $0.04 \pm 0.06 \mu \mathrm{m}^{3} \mu \mathrm{m}^{-2}$ for coarse mode; mean effective radii are $0.40 \pm 0.19 \mu \mathrm{m}$ for total, $0.14 \pm 0.02 \mu \mathrm{m}$ for fine and $1.96 \pm 0.41 \mu \mathrm{m}$ for coarse mode.

The most relevant features are the clear bimodality of the volume particle size distribution, with a slight dominance of the coarse mode in the overall climatology given the prevailing atmospheric conditions at the site (coastal marine). There is a clear prevalence of the coarse mode in summer

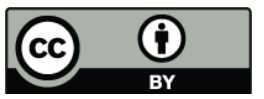

Correspondence to: N. Prats (npratsp@aemet.es) months plus September and March, in coincidence with the occurrence of desert dust intrusions and highest AOD values. During desert dust outbreaks, the particle size distribution is practically monomodal with strong prevalence of the coarse mode which also shows a shift of the modal radius toward lower values.

The size particle predominance defines the characteristic of the site and it has been analysed under two different parameters: the Ångström exponent and the fine mode volume fraction $\mathrm{Vf} / \mathrm{Vt}$. We investigated the relationship between them and also their relationship with the effective radius of the size distribution.

\section{Introduction}

According to the latest IPCC-Report (2007), the direct radiative forcing by atmospheric aerosols is now better understood and assessed than in previous reports. The accurate knowledge of this issue is very important, since small changes in the direct radiative forcing could produce the change from a cooling effect to a warming effect. Because of that, it is important to know the aerosol optical properties at global and regional scales. In order to improve the spatial and temporal knowledge of aerosol properties, worldwide networks were developed, like the AERONET (AErosol RObotic NETwork, Holben et al., 1998) operating since 1996, PFR-GAW (Precision Filter Radiometer - Global Atmosphere Watch), SKYNET (SKY radiometer NETwork) and others.

As part of global and regional networks, El Arenosillo station (Huelva, Spain) was the first AERONET site operating in the Iberian Peninsula and providing routine monitoring of atmospheric aerosols since 2000, thanks to the collaborative

Published by Copernicus Publications on behalf of the European Geosciences Union. 
effort of the Atmospheric Optic Group of the Valladolid University (GOA-UVA), Instituto Nacional de Técnica Aeroespacial (INTA) and the Laboratoire d'Optique Atmosphérique (LOA) of the University of Lille. This site has a large data-set thanks to the favourable sky conditions. Due to the variety of air masses crossing over the site, it results in a high variability of aerosol type and properties: marine, desert dust, continental and biomass burning (Toledano et al., 2009), but with the prevalence of maritime type. This site is representative of the regional area of southwestern Spain, as it has been shown in a series of publications (Toledano et al., 2007,a, b; Bennouna et al., 2011), in which it was demonstrated that its geographical location is very relevant for aerosol studies, especially for monitoring of Saharan dust outbreaks, with minor local anthropogenic (pollution) influence.

In previous works (Vergaz et al., 2005; Toledano et al., 2007a) the columnar aerosol properties at El Arenosillo area were characterized by means of the aerosol optical depth (AOD) and the Ångström exponent (AE). Both parameters are well known in the field of atmospheric aerosol studies and represent the first key properties for the aerosol characterization, giving information about the load and the predominant size of the aerosol. An air mass classification and analysis of aerosol types based on air mass origin was performed by Toledano et al. (2009), as well as an inventory of African desert dust events over the region (Toledano et al., 2007b).

The aim of the present work is to extend and complement the characterization of the atmospheric aerosol by studying the microphysical properties provided by the AERONET inversion algorithm, in the frame of the previous studies cited above. Specifically the aerosol particle size distribution and related parameters were analysed, like particle volume concentration, fine to total volume concentration fraction and effective radius, and their relations with the AOD and AE. The size particle predominance in this area is also evaluated by means of two complementary parameters: the $\mathrm{AE}$ and the fine mode volume concentration fraction $(\mathrm{Vf} / \mathrm{Vt})$.

The paper is structured as follows: first some information about the site, instrument and database status is given. Section 3 provides a brief description of the AERONET inversion algorithm and a discussion about limitations of its use. Section 4 provides the analysis of time series and the statistical characterization of the already mentioned aerosol microphysical properties. Finally the conclusions are given in section 5 .

\section{Site, instrument and database}

\subsection{Site}

The atmospheric sounding station El Arenosillo belongs to INTA and is located at the Spanish Atlantic coast $\left(37.1^{\circ} \mathrm{N}\right.$, $6.7^{\circ} \mathrm{W}$, sea level), $30 \mathrm{~km}$ east of Huelva city and close to Doñana National Park. Apart of the sea-land inhomoge- neous albedo (the site is $1 \mathrm{~km}$ away from the shore), the free-horizon terrace of the building is surrounded by a uniform Mediterranean pine forest giving a constant and low surface albedo throughout the year. Favourable weather conditions, with about $75 \%$ of clear-sky days along the year make this station an excellent site for radiation and remotesensing aerosol studies.

Depending on the season, typical synoptic situations favour the arrival of different air masses (Escudero et al., 2005, Toledano et al., 2009). Especially during late winter and summer the Saharan air masses are very frequent (Toledano et al., 2007b), changing considerably the aerosol characteristics of the site, i.e. higher aerosol optical depth and lower Ångström exponents. Toledano et al. (2009) showed the presence of Atlantic air masses in $60-70 \%$ of the days, but the wide range of Ångström exponent for these air masses could indicate mixture with local and continental aerosols, as well as different relative humidity (Hess et al., 1998). Saharan dust intrusions occur on about $20 \%$ of the days. Also, local pollution due to the nearby Palos-Huelva industrial belt has its influence on surface aerosols at the site (Sorribas, 2008), but its effect on columnar aerosol properties has not yet been quantitatively evaluated.

\subsection{Instrument and database}

This work is based on AERONET level 2 data and these data are public and free for research. The AERONET archive is divided into 3 quality levels: level 1.0 for raw data, level 1.5 for cloud-screened data and level 2.0 for quality assured data (Holben et al., 1998; Smirnov et al., 2000). However, level 2.0 data, that provide consistent information, are not always available or there are not enough data to make a reliable analysis (Prats, 2009). Different photometers are operated successively at one site, with different instrumental issues, not always described by AERONET. The user must take into account that level 1.0 and 1.5 are subject to changes after post-calibration. According to AERONET protocols, one sun-photometer should operate for approximately one year at the site, and then be replaced and sent for calibration.

The sun-photometer CE-318 family are the standard instruments in AERONET, and it has been extensively described in Holben et al. (1998). Despite the differences, all of them used the standard nominal wavelengths of 440 , 670,870 and $1020 \mathrm{~nm}$ for aerosol studies. These instruments perform two types of measurements: direct Sun irradiance, and sky radiances in the solar almucantar and principle plane geometries, which are used to retrieve aerosol properties from inversion algorithms. Direct measurements provide also aerosol optical depth for each wavelength available on each photometer type, and Ångström exponent. For climatological studies the Ångström exponent (expressed in the present paper as AE) is calculated usually for the three following nominal wavelengths: 440,670 and $870 \mathrm{~nm}$. 


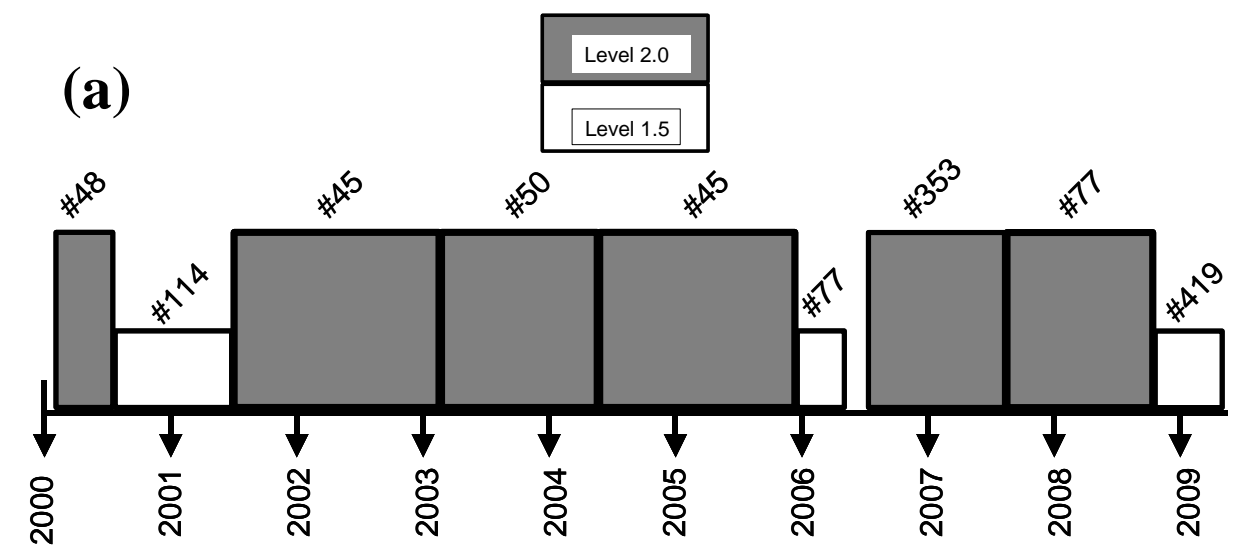

(b)

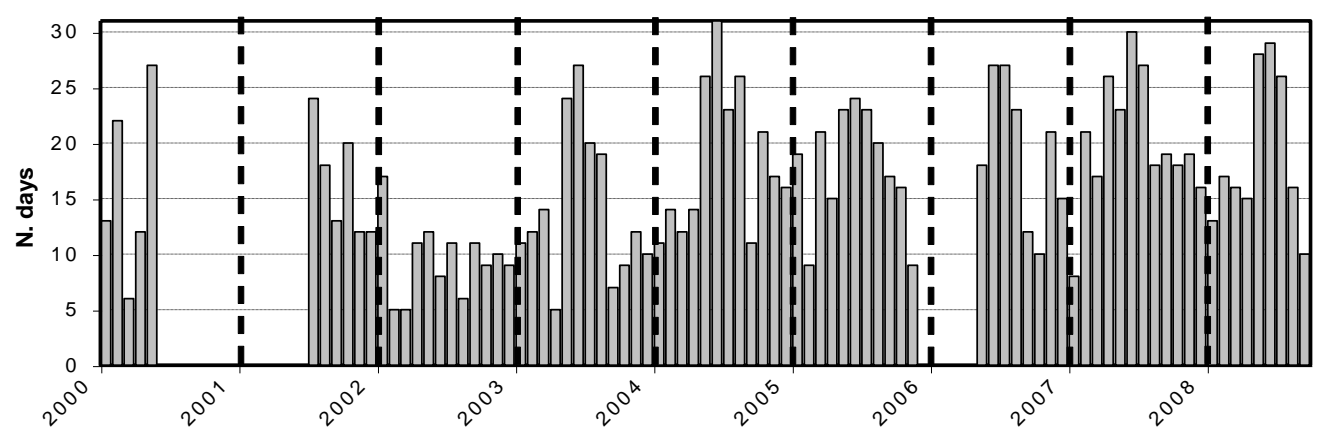

Fig. 1. (a) Cimel sun photometers operating at El Arenosillo site, labelled with AERONET numbers; (b) Number of daily inversion data in level 2 per month.

In this study the level 2.0 data from February 2000 until October 2008 are analysed. Up to now, nine different instruments have operated at our site, as shown in Fig. 1a, with the data level information for each photometer. Figure $1 \mathrm{~b}$ shows the number of days per month with level 2.0 data of microphysical parameters. More inversion data are obtained during the summer months than in winter, mainly due to the better weather conditions. Overall, 1452 days with level 2.0 inversion data are available, i.e. $46 \%$ of days in the 9 -year period, whereas the level $2.0 \mathrm{AOD}$ data reach $68 \%$ of coverage. Only two photometers have not reached level 2.0. Data from instrument \#114 (July 2000 until June 2001) are in level 1.5 because of miscalibration problems (Cachorro et al., 2008). A thunderstorm affected the sun-photometer \#77 destroying the electronics, therefore it was not possible to perform the calibration post-deployment (January 2006 until April 2006). Even using level 2.0 data, knowledge about the operational issues of the photometers is of great importance for the correct analysis of the data.

\section{Aeronet inversion algorithm}

The AERONET inversion algorithm (Dubovik and King, 2000; Dubovik et al., 2006) provides aerosol optical properties in the total atmospheric column derived from the direct and diffuse radiation measured by AERONET Cimel sunphotometers. Specifically, the AERONET code inverts sky radiances for the complete solar almucantar together with measurements of aerosol optical depth (AOD) at the same wavelengths $(440,670,870$ and $1020 \mathrm{~nm})$, to derive the particle size distribution and the complex refractive index.

The work presented by Dubovik and King (2000) was significantly different from other previous inversions (Nakajima et al., 1996; Wendish and Hoyningen-Huene, 1994; to cite some of them). It developed the simultaneous retrieval of the particle size distribution and complex refractive index via simultaneous fitting of the AOD and the almucantar radiances measured in the entire available angular range at the four mentioned wavelengths $(440,670,870$ and $1020 \mathrm{~nm})$.

In the AERONET inversion algorithm the statistically optimized inversion and corresponding retrieval error estimates are obtained under the assumption of uncorrelated log normal errors. This optimization accounts for different levels of accuracy in the measurements, assuming the standard deviation 
Table 1. Errors (\%) in the volume particle size distribution according to Dubovik et al. (2000). ( $V=$ volume particle concentration; $r=$ particle radius).

\begin{tabular}{llll}
\hline & \multicolumn{3}{c}{$d V / d \ln r\left(r_{i}\right),(\%)$} \\
\hline & Water-Soluble & Dust & Biomass Burning \\
$0.1 \mu \mathrm{m}<r<7 \mu \mathrm{m}$ & 15 & 35 & 25 \\
$r<0.1 \mu \mathrm{m}$ and $r>7 \mu \mathrm{m}$ & $15-100$ & $35-100$ & $25-100$ \\
\hline
\end{tabular}

for error in AOD for each wavelength as 0.01 and the standard deviation for error in sky radiance measurements as $5 \%$ (Dubovik and King, 2000; Dubovik et al., 2000). Possible systematic offsets originating from instrument degradation or calibration uncertainty are also considered. For the case of the particle volume size distribution, ranging for radii between 0.05 and $15 \mu \mathrm{m}$, the estimated errors are shown in Table 1 (Dubovik et al., 2000). This estimation of the error corresponds to the version 1 of the algorithm inversion; for version 2 there is no specific information.

The AERONET retrieval provides a set of additional parameters and flags that are helpful for the assessment of the retrieval quality and for a comprehensive interpretation of the aerosol retrieved data. These outputs include both retrieved aerosol parameters (i.e. volume size distribution, complex refractive index and partition of spherical/non-spherical particles) and those calculated on the basis of the previously retrieved aerosol properties (e.g. phase function, single scattering albedo, broad-band fluxes, etc.).

The main improvements of version 2 retrieval algorithm (Holben et al., 2006), used in the present study, are the internal evaluation of the spherical and spheroid models, the characterization of the surface albedo for different types of surfaces, and a change in the restrictions to assure the quality of the inversion. A set of restrictions was developed according to sensitivity studies (Dubovik et al., 2000).

There are two important limitations according to these sensitivity studies. The first one is that the solar zenith angle (SZA) must be larger than $50^{\circ}$. Almucantars close to local noon are not used, therefore it is not possible to have continuity throughout the day. This problem could be solved using principal plane data as shown in Olmo et al. (2008). Typically 8 almucantars are measured everyday at SZA larger than $50^{\circ}$. The other severe restriction is that the AOD for $440 \mathrm{~nm}$ must be greater than 0.4 to retrieve the single scattering albedo and complex refractive index. This strong limitation does not apply to the retrieval of the microphysical properties, which are the subject of this study.

Specifically, the microphysical parameters analysed in this work are the aerosol volume particle size distribution (VPSD) and its derived parameters: the volume concentration $\left(V_{\mathrm{c}}\right)$ of the total size distribution (VolCon-T), the fine mode (radius from 0.05 to $\sim 0.6 \mu \mathrm{m}$, VolCon-F) and the coarse mode (from $\sim 0.6 \mu \mathrm{m}$ to $15 \mu \mathrm{m}$, VolCon-C), as well as the effective radius (Eff.R. or $R_{\text {eff }}$ ) for total, fine and coarse mode, defined as:

$$
\begin{aligned}
& V_{\mathrm{c}}=\int \frac{d V(r)}{d \ln r} d \ln r \\
& R_{\mathrm{eff}}=\frac{\int r^{3} \frac{d N(r)}{d \ln r} d \ln r}{\int r^{2} \frac{d N(r)}{d \ln r} d \ln r}
\end{aligned}
$$

Although the AERONET database provides values of both parameters, the geometrical mean or median radius and effective radius, we have chosen the effective radius for describing the size of the aerosol particles because single scattering properties of the size distribution are closer related to effective radius than to median radius (Hansen and Travis, 1974).

\section{Results}

In this section the microphysical aerosol parameters are analysed in order to characterize their time series and representative mean statistical values. We will also relate the results to the previous knowledge of AOD and AE given by Toledano et al. (2007a and 2009), that provided the first characterization of columnar aerosols.

\subsection{Volume particle size distribution}

To illustrate the main features and the values of the VPSD, the monthly averaged values for the entire dataset have been calculated, from the daily mean values. To see detailed and specific examples of the VPSD behaviour under different situations related with low and high turbidity conditions we refer the reader to a previous work (Prats et al., 2008). In Fig. 2 the mean VPSD value for every month is shown together with a table of the monthly mean of AOD at $440 \mathrm{~nm}(\mathrm{AOD}(440))$ and AE. First of all, the high variability of the coarse mode concentration stands out (i.e. the value at the peak varies from $0.008 \mu \mathrm{m}^{3} \mu \mathrm{m}^{-2}$ in December up to $0.038 \mu \mathrm{m}^{3} \mu \mathrm{m}^{-2}$ in August) in comparison with the fine mode variability (between 0.013 and $0.023 \mu \mathrm{m}^{3} \mu \mathrm{m}^{-2}$ ), as well as the predominance of the coarse mode concentration for the summer months and March. Although summer months are considered from June to August, September may also be considered as part of the summer in the south of Spain. This issue is related to the frequency of desert dust intrusions, as shown in the desert dust inventory performed by Toledano et al. (2007b). It was found that the desert dust episodes are more frequent in February-March and the summer months. It should be noted that the high values of September (see fine mode concentration) are due to an exceptional desert dust event registered in 2007 (GuerreroRascado et al., 2009), as it will be shown in the next section. During the winter months the fine mode predominates and the month-to-month differences are smaller. 


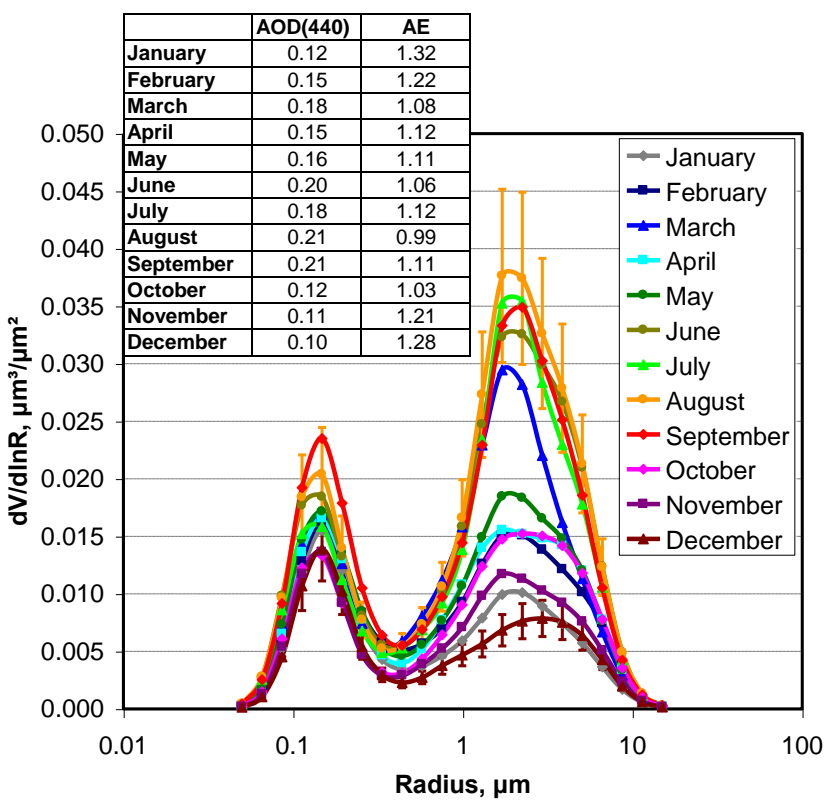

Fig. 2. Multi-annual monthly average of volume particle size distribution. Table shows the monthly averages of AOD $(440 \mathrm{~nm})$ and AE $(440-870 \mathrm{~nm})$, fitted in the range 440 to $870 \mathrm{~nm}$. Error bars are added to the highest (August) and lowest month (December) to illustrate the uncertainty of the measurements, about $20 \%$ in the range $0.1 \mu \mathrm{m}<r<7 \mu \mathrm{m}$ according to Dubovik et al. (2000).

The lowest VPSD, not only for coarse mode but also for fine mode, is obtained in December, in agreement with the minimum AOD for this month. The highest VPSD are found in summer due to the highest turbidity. Because of the strong and also variable influence of desert dust intrusions, the fine and coarse modes also present a greater variability during this season. Within the analysed period, the highest value for the fine mode concentration is found in September and for the coarse mode in August (associated with the summer AOD maximum of 0.21 in September and August). The lowest mean value of the Ångström exponent is measured during August (0.99) in this data series, corroborating the desert dust influence. The fact that September also presents the maximum of AOD, with a relative low value of $\mathrm{AE}$, is a particularity of the analysed period due to the already mentioned specific strong intrusion of 2007 (Guerrero-Rascado et al., 2009), but it is likely that this maximum will disappear as the dataset includes more years of measurements.

There is almost a factor 2 difference in the coarse modal radius in August $(1.71 \mu \mathrm{m})$, in which the highest concentration was observed, and December $(3.00 \mu \mathrm{m})$, in which we observed the lowest coarse mode concentration. It could be derived from this behaviour that the peak concentration grows when the modal radius decreases. However the correlation between these two magnitudes (concentration and modal radius of the coarse mode), is very poor and is not observed in the data (nor in the long-term averages in Fig. 2).
Furthermore, the estimated uncertainty in the size distributions (about 20-35\% in volume concentration within the size range $0.1-7 \mu \mathrm{m}$, see Table 1 ) does not allow deriving any further conclusion on this. Only in desert dust cases the VPSD was transformed to a practically monomodal function with a high coarse mode concentration and the modal radius shifted to lower values (Prats et al., 2008). Such behaviour was already reported in other works as those of Eck et al. (2001) in a monsoon study over the Kaashidhoo Island, in the Republic of Maldives, and Olmo et al. (2006) in south-east Spain. However, in Eck et al. (2005) the particle coarse mode radius does not show a clear trend in decreasing size as a function of increasing AOD, in agreement with what occurs in our case. It is also interesting to emphasize the existence and superposition of two or even three modes over the coarse mode size distributions in some cases, e.g. in April. Finally, the modal radius of the fine mode is essentially constant along the year, with values around $0.14 \mu \mathrm{m}$.

\subsection{Volume particle concentration}

Table 2 shows the general statistics of the volume particle concentration (VPC) for the analysed period, derived from the volume particle size distribution according to Eq. (1). The mean values for the particle volume concentration are $0.06,0.02$ and $0.04 \mu \mathrm{m}^{3} \mu \mathrm{m}^{-2}$ for the total, fine and coarse mode, respectively. It must be noted that in all cases the standard deviation is similar to the mean, indicating the high variability of the data. The difference between the mean and the median total concentration, 0.06 versus $0.04 \mu \mathrm{m}^{3} \mu \mathrm{m}^{-2}$, shows that the predominant situations at El Arenosillo are those with values of total concentration lower than the mean (also low AOD), in accordance with the coastal maritime character of the site. However, the strong contribution of the coarse mode to the total volume concentration indicates that, although the desert dust events are less frequent than maritime aerosol conditions, they have a substantial impact and determine the general characteristics of the site. To identify this fact, Fig. 3 shows the monthly mean time series of the total volume particle concentration. A first look shows the different behaviour from one year to another, and although in general the highest concentration is found in the summer months, also few relative maxima appear in the late winter and early spring because of desert dust events. However, as it can be seen high values may also appear in other months. The extraordinary high values in several months, like September 2007, July 2004 or March 2000, are due to these strong Saharan dust events.

The year to year and monthly variability is given in Fig. 3; Fig. 4 depicts the general repeatable long term using the monthly average or multi-annual behaviour of the particle volume concentration together with the $\mathrm{AOD}(440)$. In this figure we can better observe the similar behaviour of the total and coarse mode particle volume concentration with the AOD for the seasonal evolution. As observed in the earlier 


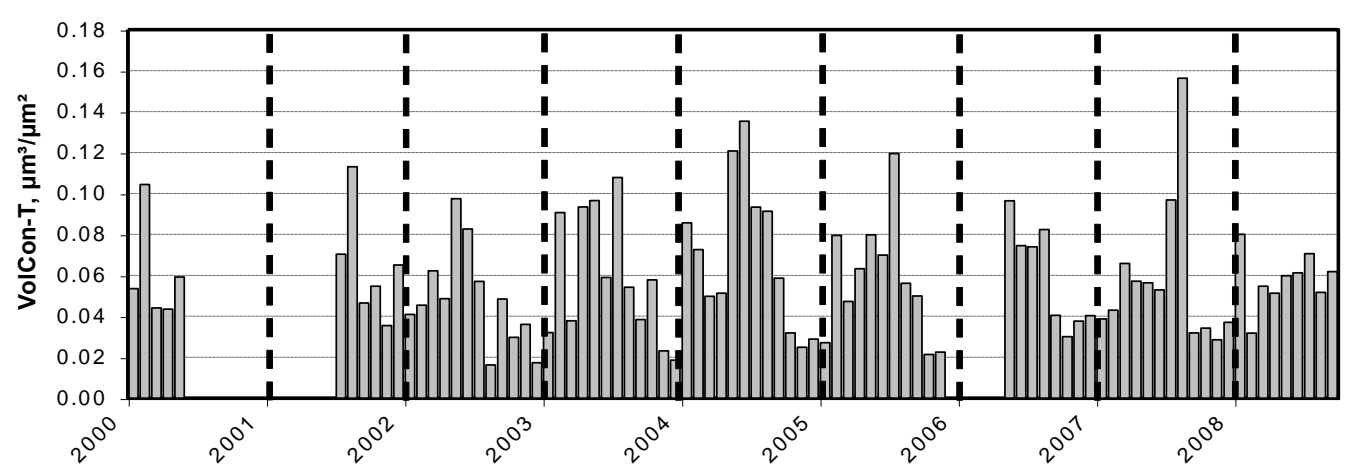

Fig. 3. Monthly average of total volume particle concentration for each year. Note the very high values in September 2007.

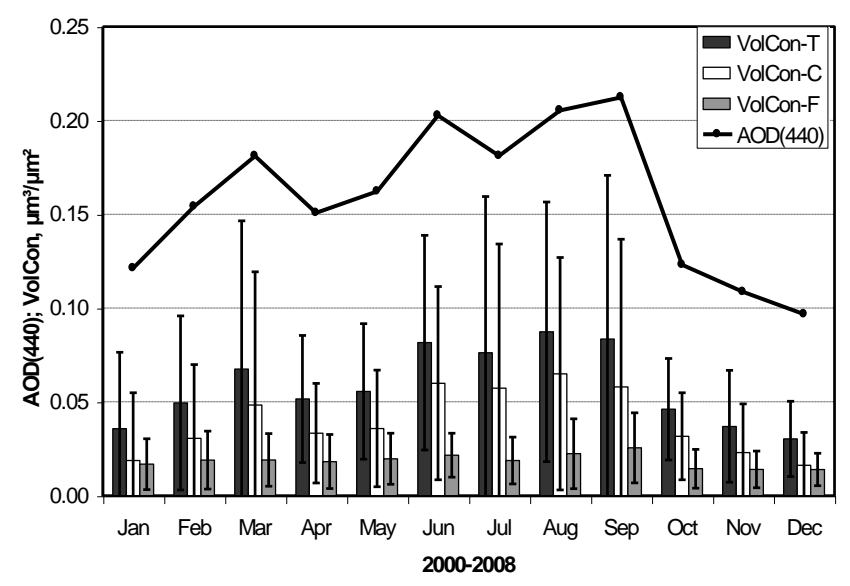

Fig. 4. Multi-annual monthly average of the volume particle concentration total (black), coarse (white) and fine (grey) mode (vertical bars indicate standard deviation). The solid line represents the monthly average values of the AOD at $440 \mathrm{~nm}$.

Fig. 3, the highest values appear for summer months plus September $\left(0.09 \mu \mathrm{m}^{3} \mu \mathrm{m}^{-2}\right.$ for total and $0.06 \mu \mathrm{m}^{3} \mu \mathrm{m}^{-2}$ for coarse mode) but also in March $\left(0.07 \mu \mathrm{m}^{3} \mu \mathrm{m}^{-2}\right.$ for total and $0.05 \mu \mathrm{m}^{3} \mu \mathrm{m}^{-2}$ for coarse mode). This secondary maximum is due to the desert dust intrusions that occur at the end of winter and early spring period, as already mentioned. The lower values are found for winter months: $0.03 \mu \mathrm{m}^{3} \mu \mathrm{m}^{-2}$ for total and $0.02 \mu \mathrm{m}^{3} \mu \mathrm{m}^{-2}$ for coarse mode. We note the observed minimum of AOD in July, a local minimum in summer months, not observed in previous works (Toledano et al., 2007a) but assessed with new AOD added data and also observed with AOD MODIS data (Bennouna et al., 2011). The cause of this minimum in July seems to be linked to the frequency of occurrences of Atlantic air masses during summer months (ultimately due to the dynamical circulation over the Iberian Peninsula) which affect the seasonal patterns of AOD and also the columnar water vapour content (Ortiz de Galisteo et al., 2011), thus appearing as a particular characteristic of the area.
Table 2. Statistical parameters of volume particle concentration (VolCon) of total, fine and coarse mode, fine mode volume fraction (Vf/Vt), AOD for $440 \mathrm{~nm}$ and $\mathrm{AE}$ at El Arenosillo site for the period February 2000-October 2008 (level 2.0). STD=standard deviation.

\begin{tabular}{lllllll}
\hline \multicolumn{7}{c}{ VolCon $\left(\mu \mathrm{m}^{3} \mu \mathrm{m}^{-2}\right)$} \\
\hline Mean & Total & Fine & Coarse & $V_{f} / V_{t}$ & $\mathrm{AOD}(440)$ & $\mathrm{AE}$ \\
STD & 0.06 & 0.019 & 0.04 & 0.39 & 0.16 & 1.14 \\
Median & 0.07 & 0.015 & 0.06 & 0.19 & 0.13 & 0.41 \\
Percentile 10 & 0.04 & 0.015 & 0.03 & 0.37 & 0.13 & 1.21 \\
Percentile 90 & 0.13 & 0.006 & 0.01 & 0.15 & 0.06 & 0.50 \\
Maximum & 1.13 & 0.173 & 0.10 & 0.67 & 0.32 & 1.63 \\
Minimum & 0.004 & 0.002 & 0.001 & 0.92 & 1.61 & 2.35 \\
& & & & & 0.02 & 0.03 \\
\hline
\end{tabular}

Although difficult to observe in Fig. 4, the fine mode volume concentration follows the same behaviour as described above for the coarse mode, with values slightly higher for summer and March (larger than $0.021 \mu \mathrm{m}^{3} \mu \mathrm{m}^{-2}$ ) and lower during the winter months (below $0.015 \mu \mathrm{m}^{3} \mu \mathrm{m}^{-2}$ ). On the other hand, the time series of daily mean values of volume particle concentrations (not shown here) runs roughly parallel to the AOD, particularly for the coarse and total particle volume concentration.

In Fig. 5 the relation of the AOD $(440 \mathrm{~nm})$ versus total volume concentration is shown. Bearing in mind the definition of extinction efficiency (equivalent to the mass extinction efficiency or the mass scattering efficiency, Wagoner et al., 1981) for these columnar quantities, we can interpret the slopes of this plot (not shown). The most relevant feature in Fig. 5 is the existence of two well defined branches, which are associated with the aerosol type, being the lower branch related to coarse-mode dominated aerosols (most red points), i.e. desert dust for high values and marine for low values, giving an average extinction efficiency Ef $(440 \mathrm{~nm})$ of $1.8 \mu \mathrm{m}^{2} \mu \mathrm{m}^{-3}$ (AOD per unit of particle volume concentration). The upper branch contains the fine mode dominated cases, such as clean continental (low values), polluted (intermediate values), biomass burning (high values), where the average extinction efficiency factor may be estimated 


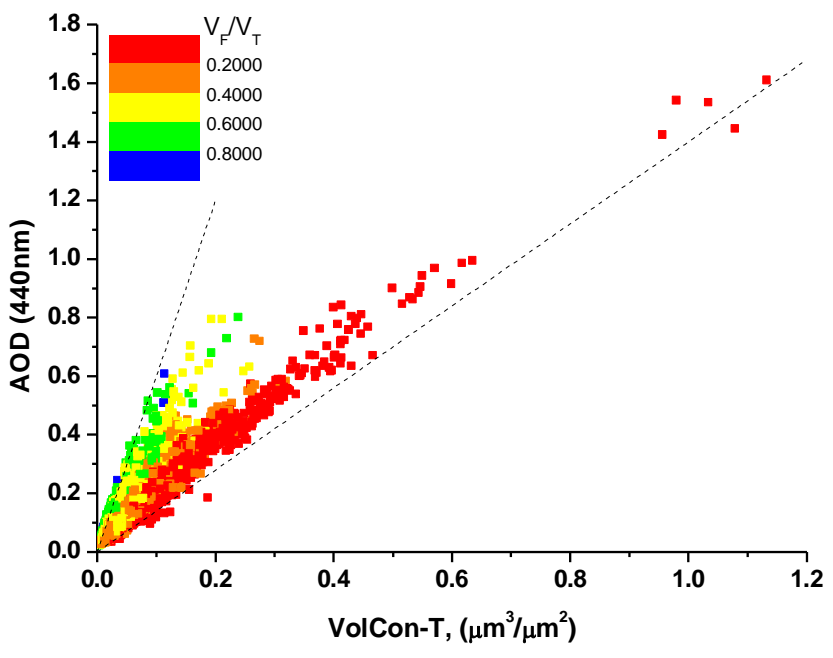

Fig. 5. Scatter plot between AOD $(440 \mathrm{~nm})$ and total volume particle concentration as a function fine mode volume fraction (binned by five values, color scale). Dashed lines represent the extreme values of the extinction efficiency factor.

as $3.5 \mu \mathrm{m}^{2} \mu \mathrm{m}^{-3}$. The two dashed lines in Fig. 5 represent the extreme values of the extinction efficiency at $440 \mathrm{~nm}$ of $1.4 \mu \mathrm{m}^{2} \mu \mathrm{m}^{-3}$ for coarse particles and $6 \mu \mathrm{m}^{2} \mu \mathrm{m}^{-3}$ for fine particles. We have highlighted in this Fig. 5 the values of the ratio of fine mode concentration to the total volume concentration $(\mathrm{Vf} / \mathrm{Vt})$ by bin-colour scale, to emphasize the prevalence of coarse particle (values of $\mathrm{Vf} / \mathrm{Vt}$ between 0 . to 0.4 ) (see next paragraph).

Therefore we call attention that Figs. 4 and 5 give a good representation of the extensive aerosol magnitudes in a given site, as part of its general characterization. Figure 5 also gives insight about the presence of different aerosol types over the site. A deep analysis of the aerosol type about microphysical or other optical properties, as single scattering albedo, is not the aim of this work and hence further studies are necessary in this context, also linked with other areas of the Iberian Peninsula.

\subsection{Fine mode volume fraction}

The fine mode volume fraction $\mathrm{Vf} / \mathrm{Vt}$ is defined as the ratio between fine mode particle volume concentration (VolConF) and total particle volume concentration (VolCon-T). Hence, this fraction is a relevant parameter for determining the predominance of the fine or coarse mode. Because of this, it is interesting to analyse the scatter plot of this fraction versus the Ångström exponent, which traditionally is being used as a qualitative indicator to characterize the particle size (Eck et al., 1999; O'Neil et al., 2001; Cachorro et al., 2001), i.e. for the identification of the aerosol type.

The spectral dependence of the AOD is given traditionally by the $\mathrm{AE}$ and this is related to the particle size predominance (Ångström, 1961; Shifrin, 1995). It is well known that the higher the concentration of the coarse mode (like for desert dust aerosol) the lower the Ångström exponent (Eck et al., 1999; O'Neil et al., 2001; Schuster et al., 2006), and the higher the values of Ångström exponent the higher the dominance of the fine particles (like for biomass burning aerosol).

When the aerosol particle size distribution is taken according to the Junge function, a direct relationship is found between the AE and the Junge parameter (Junge, 1963, Cachorro and De Frutos, 1995), which does not account for the curvature of the AOD. The size distribution is assumed monomodal and hence the $\mathrm{AE}$ is linearly well correlated with the geometrical and the effective radius (Cachorro et al., 2001; Schuster et al., 2006). Otherwise, when the particle size distribution has two size modes, the ratio of concentrations (given in number, surface or volume) also modulates and determines the spectral shape of the AOD, as demonstrated by Schuster et al. (2006).

However, one of the main problems using the AE is that it has a more qualitative than quantitative character, because of the approach used to relate it with the particle size distribution and, in the case of experimental measurements, the high sensitivity to AOD error. Bear in mind that the AE is determined in a certain experimental spectral range and, as demonstrated by Cachorro et al. (2001), this parameter shows a high dependence on the spectral range considered for its determination. Furthermore, there is no general consensus for a unique given range and also we must consider that the longer the spectral range we choose the poorer the linear approximation (AE) is, because of the mentioned curvature of real AOD spectra. The AERONET Ångström exponent for climatology analysis, which is used here, is determined using 3 wavelengths: 440,670 and $870 \mathrm{~nm}$.

Specifically, Schuster et al. (2006) determined the Ångström exponent for 7 wavelengths, between 340 and $1020 \mathrm{~nm}$. According to their analysis, $\mathrm{AE}(340-1020)$ values lower than 1 were related to cases clearly dominated by coarse particles, whereas $\mathrm{AE}(340-1020)>2$ indicates predominance of fine particles. However, it is not possible to determine the size predominance for $1<\mathrm{AE}(340-1020)<2$, precisely the most frequent range for atmospheric aerosols. Within this range the $\mathrm{AE}$ parameter shows a great scatter when plotted versus other size-related parameters, such as the effective radius and the fine mode volume fraction. It is not easy to establish a well defined threshold for fine or coarse particle predominance in terms of the $\mathrm{AE}$ parameter as can be seen in different works in the literature (Eck et al., 1999, 2005). In spite of all these drawbacks the AE parameter is widely used in aerosol studies as a first insight about size particle because it is simple to obtain.

Both parameters, $\mathrm{AE}$ and the ratio $\mathrm{Vf} / \mathrm{Vt}$, are related to particle size and then a correspondence between them is to be expected, in order to characterise fine and coarse particle predominance (taking into account the above cited results by Schuster et al. (2006)). Furthermore the AE vs. Vf/Vt plot 

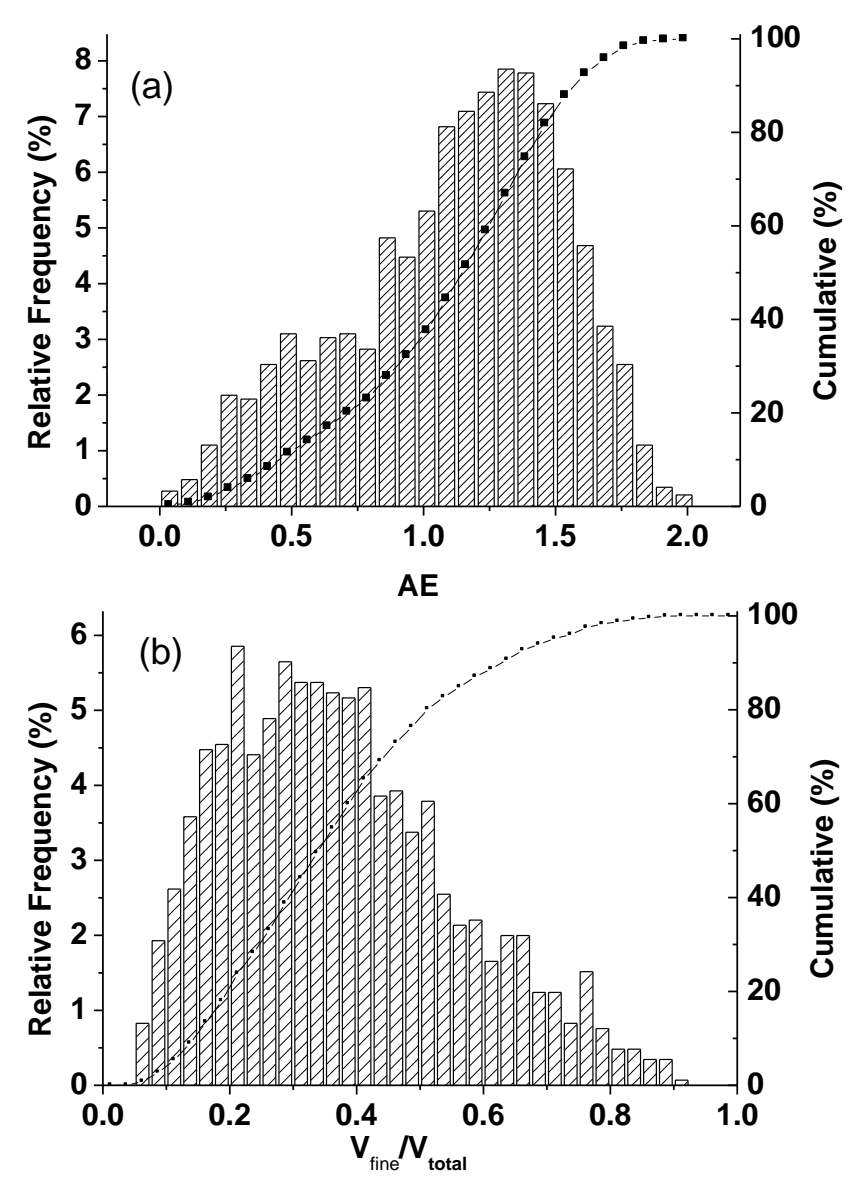

Fig. 6. Normal and cumulative Frequency of (a) the Ångström exponent and (b) fine mode volume fraction.

(Fig. 7) as a whole also defines the aerosol characteristics at the study site.

To set up the quantitative limit between coarse and fine particle predominance according to the $\mathrm{AE}$ values at El Arenosillo, the frequency histogram of this parameter (Fig. 6a) has been analysed. In this histogram we observe a bimodality with a minimum at $\mathrm{AE}=0.75$, separating situations where coarse particles predominate (mainly due to maritime aerosol or Saharan dust intrusions). Below this threshold in $\mathrm{AE}$ we find $23 \%$ of the measurements. If the limit between coarse and fine predominance is fixed in the literature at about $\mathrm{AE}=1$, this means that in this $37 \%$ of observations there is a prevalence of coarse particles. If this threshold is extrapolated to Fig. 7, which shows the scatter plot of AE versus fine mode volume fraction, we can observe that for measurements with $\mathrm{AE}<0.75$ there are no data with $\mathrm{Vf} / \mathrm{Vt}>0.5$. For $\mathrm{AE}=0.75$ the $\mathrm{Vf} / \mathrm{Vt}$ varies from 0.15 to 0.45 . According to Fig. 7 we would establish the limit of the fine particle predominance in $\mathrm{AE}>1.8$ approximately, since for higher $\mathrm{AE}$ values there are almost no data with $\mathrm{Vf} / \mathrm{Vt}<0.5$.

But for $0.75<\mathrm{AE}<1.8$, the $\mathrm{Vf} / \mathrm{Vt}$ ranges predominantly between 0.2 and 0.8 , which represents a great scatter and

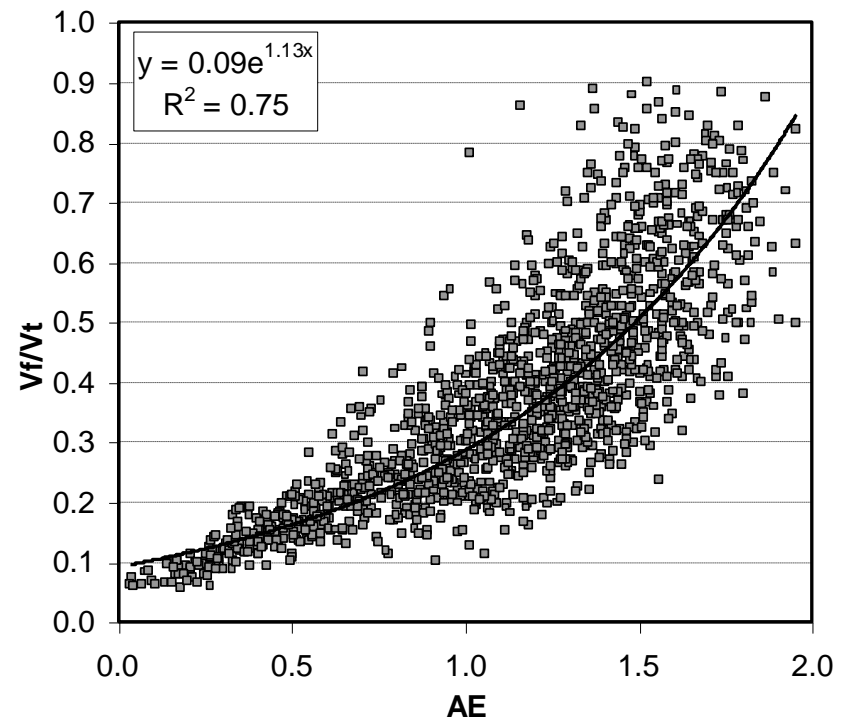

Fig. 7. Scatter plot between Ångström exponent and fine mode volume fraction. Exponential regression is also shown.

hence it is not possible to a priori establish the predominance of fine or coarse particles. However, we have tried to find a quantitative relation that could be represented by an exponential formula with a determination coefficient of $R^{2}=0.75$ (Fig. 7).

To complete the analysis of size predominance, we have considered the information provided by the fine mode volume fraction. In Fig. $6 b$ the frequency histogram and the accumulative values are shown. Figure $6 \mathrm{~b}$ indicates that $76 \%$ of the observations correspond to coarse particle predominance $(\mathrm{Vf} / \mathrm{Vt} \leq 0.5)$.

Table 2 summarizes the statistics for AE using level 2.0 inversion data. Mean value is 1.14 (the median is 1.21), which according to Fig. 7 falls inside the area where there is no clear relation between $\mathrm{AE}$ and $\mathrm{Vf} / \mathrm{Vt}$. On the other hand, also in Table 2 the mean for the ratio Vf/Vt is 0.39 and the median value is 0.37 , which according to Fig. 7 is also related to a large range of $\mathrm{AE}$ values (0.6-1.6). These results show that El Arenosillo station is defined by a nearly similar presence of fine and coarse particles that yield intermediate values of the $\mathrm{AE}$, maybe with a slight dominance of the fine particles considering the dataset as a whole. However in terms of volume concentration, a dominance of coarse particles is observed. Finally, Fig. 8 shows the monthly means for the analysed period for the fine mode volume fraction and the $\mathrm{AE}$ (AOD is also displayed). The $\mathrm{Vf} / \mathrm{Vt}$ values indicate a decrease from winter (0.56 in January) until March (0.36), being constant in April and May and decreasing again to 0.3 in the summer months. The seasonal pattern is nearly similar to that of the Ångström exponent, as could be expected. 


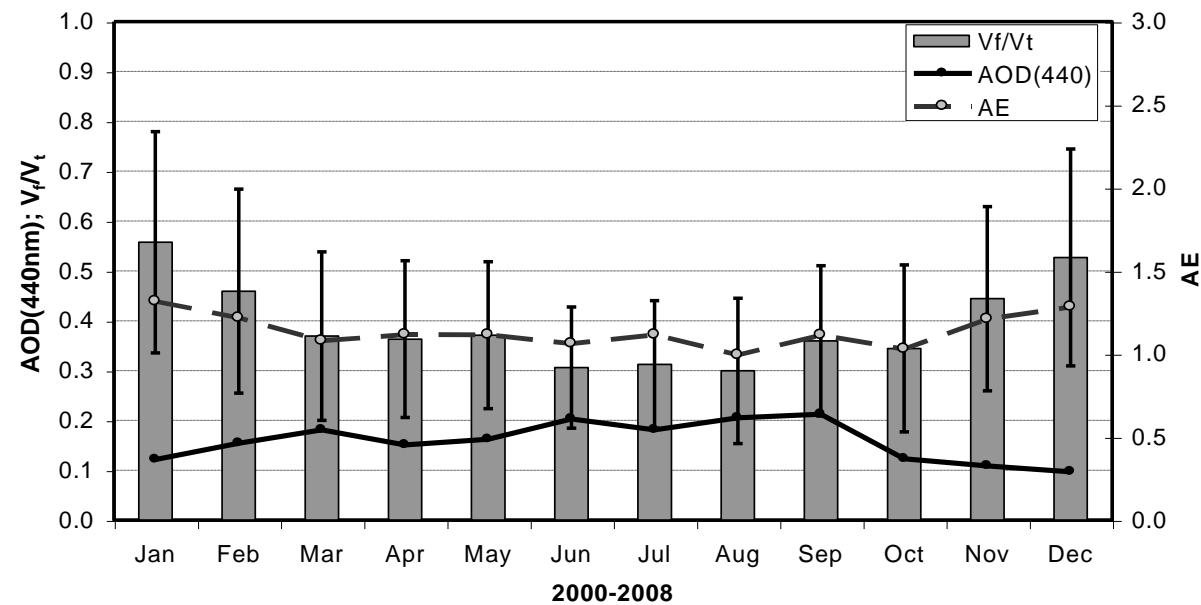

Fig. 8. Multi-annual monthly average of the fine mode volume fraction (vertical bars indicate standard deviation). Solid line represents monthly average AOD $(440 \mathrm{~nm})$. Thick dashed line indicates the AE.

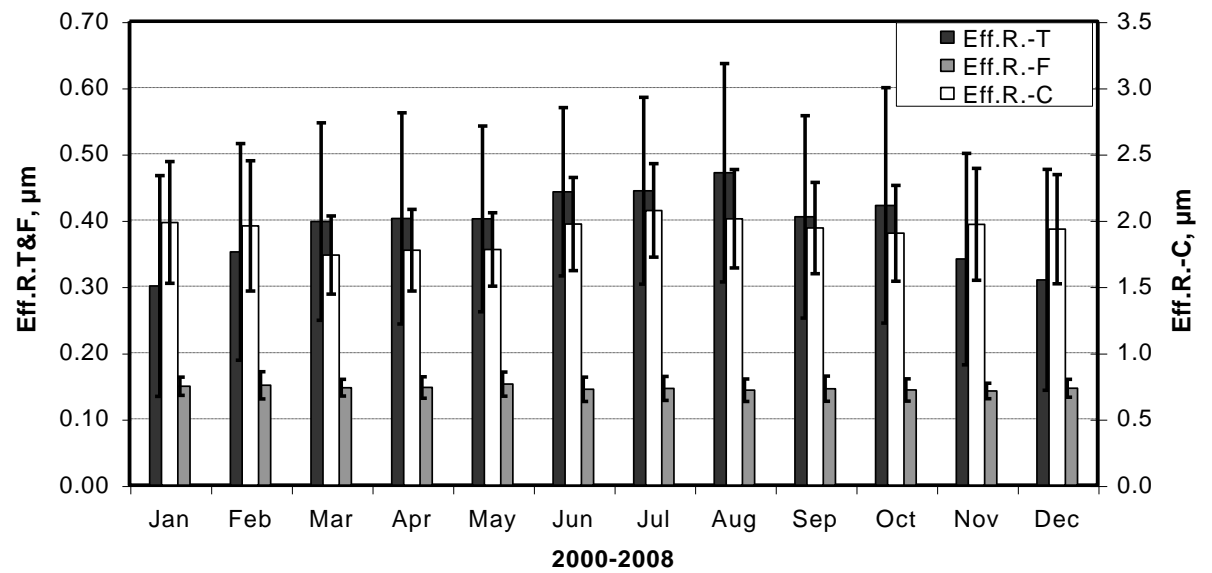

Fig. 9. Multi-annual monthly average of the effective radius of total (black), coarse (white) and fine mode (grey) (vertical bars indicate standard deviation).

\subsection{Effective radius}

As mentioned before the effective radius (instead of the geometrical mean radius) is taken to study the physical behaviour of the VPSD represented by this parameter. Hansen and Travis (1974) emphasize that the primary characteristic of any physically plausible size distribution of spherical particles is the effective radius. Schuster et al. (2006) also used the effective radius to study the relationship between particle size and Ångström exponent, as we will do in this subsection.

From a lognormal monomodal particle size distribution function, the effective and the geometrical radius differ by a constant (see Fig. 2 of Schuster et al., 2006) therefore for experimental data a good correlation must be expected between both parameters, as can be seen in Prats (2009) for the El Arenosillo dataset. The correlation was very high for the coarse mode and the fine mode respectively, both with $R^{2}=0.95$ (plots not shown). For the total size distribution the correlation was lower but significant $\left(R^{2}=0.79\right)$, but this is not an important issue because the total particle size distribution is an effective representation of a bimodal size particle distribution by a monomodal one.

The statistic about the total effective radius (Table 3) shows values that range between $0.14 \mu \mathrm{m}$ and $1.48 \mu \mathrm{m}$ with a mean value of $0.40 \mu \mathrm{m}$, and a high variability indicated by the standard deviation STD $=0.16(40 \%)$. Similar features are also obtained for the effective radius of the coarse mode, which ranges between $0.92 \mu \mathrm{m}$ and $4.42 \mu \mathrm{m}$, with mean value of $1.96 \mu \mathrm{m}$ and $\mathrm{STD}=0.41(21 \%)$. On the other hand, the fine mode effective radius presents a small variability, with a standard deviation of $0.02(14 \%)$ for a mean value of $0.14 \mu \mathrm{m}$. The near equal values of mean and median effective radius, for the total, coarse and fine mode, reveal that the size distribution is close to lognormal.

The effective radius multi-annual monthly means for total, coarse and fine modes are shown in Fig. 9. The total 
Table 3. Statistical values of effective radius (EffR) for total, fine and coarse mode at El Arenosillo site (level 2.0). STD=standard deviation.

\begin{tabular}{llll}
\hline & \multicolumn{3}{c}{ EffR $(\mu \mathrm{m})$} \\
\hline & Total & Fine & Coarse \\
Mean & 0.40 & 0.14 & 1.96 \\
STD & 0.16 & 0.02 & 0.41 \\
Median & 0.36 & 0.14 & 1.91 \\
Percentile 10 & 0.22 & 0.12 & 1.47 \\
Percentile 90 & 0.62 & 0.17 & 2.53 \\
Maximum & 1.48 & 0.28 & 4.42 \\
Minimum & 0.14 & 0.10 & 0.92 \\
\hline
\end{tabular}

effective radius show higher values in summer (around 0.44 $0.47 \mu \mathrm{m}$ ) decreasing toward the lowest in winter (around $0.30-0.35 \mu \mathrm{m}$ ), somewhat similar to the AOD seasonal behaviour (although not as close as AOD and volume concentration seasonal patterns).

With regard to the coarse mode effective radius, there is no clear seasonal pattern. The small $R_{\text {eff }}-\mathrm{C}$ in March is somewhat surprising, because an increase was expected for this month due to desert dust intrusions (as it is seen for summer). However, as indicated in section 4.1, an increase in AOD due to desert dust intrusions can entail a decrease in the coarse mode effective radius.

The fine mode effective radius appears to be constant along the year, with values around $0.15 \mu \mathrm{m}$ (Fig. 9). The constancy along the year was also observed by Gonzi et al. (2002) for 48 AERONET sites in Europe. However we must bear in mind the uncertainty of this radius because of the detected artefact of the inversion algorithm due to the poor sensitivity to this size range (Dubovik et al., 2000). Furthermore, the importance of desert dust intrusions in this area with a strong influence of non-spherical particles over this parameter may be also considered but it is difficult to evaluate.

The correspondence between the total effective radius and the AE must be plotted as a characteristic of aerosols at the site. Figure 10 shows this plot where even though there is a clear decreasing of the total effective radius for increasing $\mathrm{AE}$, we have not tried to establish a mathematical relationship because of the high scatter. The fine and coarse mode effective radii are also displayed (only for visualization because it has no physical meaning to find a correlation in this case).

In Fig. 11 we have also plotted the fine mode volume fraction and the total effective radius, as representative of the site aerosol characterization. Since both magnitudes are retrieved in the same inversion process, these results should be consistent. A high correlation represented by a power function with a coefficient of $R^{2}=0.93$ is found.

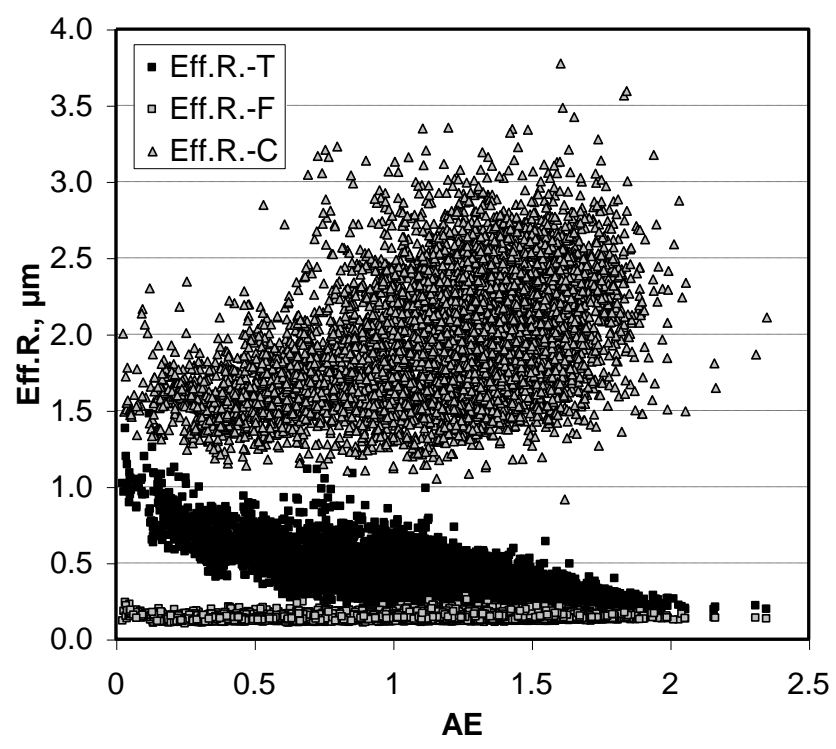

Fig. 10. Scatter plot between $A E$ and total (black squares), fine mode (grey squares) and coarse mode (grey triangles) effective radius.

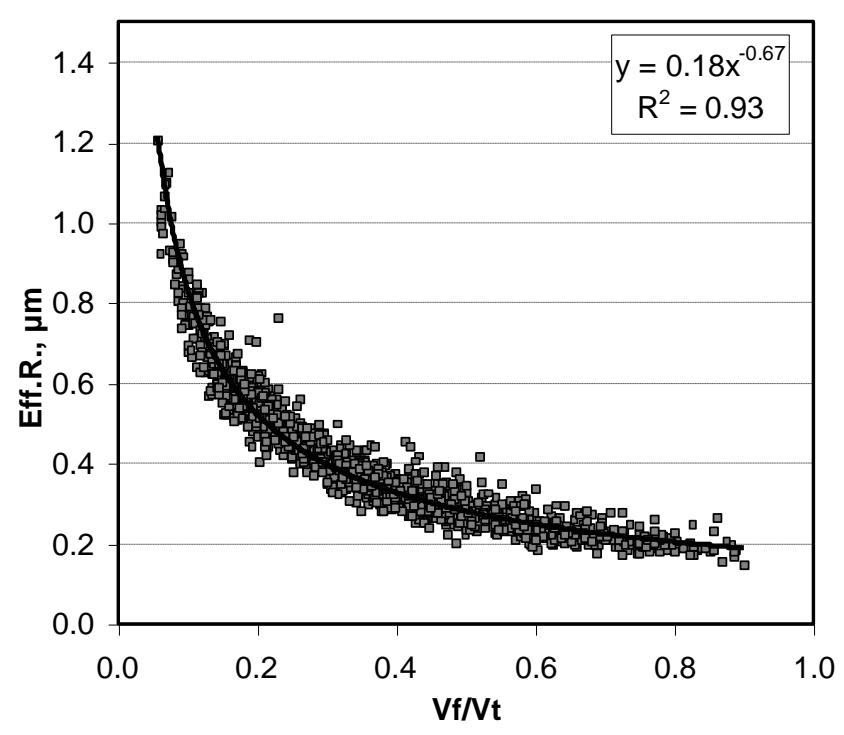

Fig. 11. Scatter plot between fine mode volume fraction and total effective radius. Black line represents the correlation by a power function.

The AE indicates the relative importance between the fine and coarse mode of the size distribution, hence a correlation between $\mathrm{AE}$ (or the volume ratio $\mathrm{Vf} / \mathrm{Vt}$ ) and the effective radius is to be expected, but not for either the fine mode or coarse mode alone. Therefore, Figs. 10 and 11 synthesise the behaviour of the intensive magnitudes of the aerosol columnar microphysical properties at El Arenosillo. 


\section{Conclusions}

The characterization of the columnar aerosol volume particle size distributions, VPSD, and derived microphysical parameters over a South-western-coastal area of Spain has been carried out. The VPSD presents a well defined bimodality for general conditions (dominance of marine coastal aerosols) but with a different weight of coarse or fine mode depending on the month. The bimodal behaviour changes for conditions of clear desert dust aerosol intrusions where the prevailing coarse mode transforms the distribution to a practically monomodal shape and shifts the coarse mode radius to lower values. The low frequency of desert dust intrusions (or Saharan air masses) is not enough to change the global bimodality of the VPSD that defines the climatology of the site, but has a marked influence showing the moderate prevalence of the coarse mode, as it is also shown by the other derived aerosol parameters.

The volume concentrations for total and coarse modes show a clear seasonal pattern with maximum in summer (plus September) and minimum in winter but with the particularity of a second maximum in March because of the influence of desert dust intrusions, whose occurrence modulates the seasonal pattern. This pattern is in fair accordance with the temporal AOD behaviour, giving good correlations between AOD and volume particle concentrations, except for the fine mode. Note the existence of two branches in the AOD-Volume concentration correlation, which clearly define the existence of two aerosol types in terms of size, being the lower branch related to aerosol dominated by coarse particles.

The fine mode volume fraction appears to be a good indicator to characterize the particle size, complementary to the Ångström exponent. The relationship between both parameters gives a good representation of aerosols in the analysed site, defined by a slight prevalence of coarse particles. It is also remarkable that the Ångström exponent, as indicator of particle size dominance, is better correlated to the fine mode volume fraction than to the effective radius of the aerosol size distribution. The reason is that assuming a monomodal aerosol size distribution, the geometrical (or effective) radius determines the spectral shape of the extinction coefficient (or AOD) and has a linear correlation with AE; but when the distribution have two particle size modes, the ratio of fine and coarse mode concentrations (given in number, surface or volume) also modulates and determines the spectral shape of AOD.

The total effective radius shows higher values in summer and lower in winter. The fine mode effective radius is practically constant along the year and apparently insensitive to aerosol type.

This study shows that further analysis is required for discriminating the microphysical properties depending on the aerosol type and its relationships with other key optical properties, such as refractive index and single scattering albedo.
The analysis of the later parameters is absolutely disturbed because of the reduction in the amount of data imposed by the requirements of the level 2 retrieval for optical parameters (i.e., AOD $>0.4$ ), making the data-record not as representative of the real aerosols in the area. In our case, level 2 optical parameters only represent desert dust aerosols.

Data and Sharing Resources: Data of this work can be downloaded from the AERONET webpage http://aeronet. gsfc.nasa.gov.

Acknowledgements. Financial support from the Spanish MICINN (projects of ref. CGL2008-05939-CO3-01/CLI and CGL200909740 and "Acción Complementaria" CGL2010-09480-E) are gratefully acknowledged. The authors thank the ESAt-El Arenosillo staff, as well as the AERONET, PHOTONS and RIMA teams for their support and collaboration.

Edited by: W. Lahoz

\section{References}

Ångström, A. Techniques of determining the atmospheric turbidity, Tellus 16(1), 64-75, 1961.

Bennouna, Y. S., Cachorro, V. E., Toledano, C., Berjón, A., Prats, N., Fuertes, D., Gonzalez, R., Rodrigo, R., Torres, B., and de Frutos, A.: Comparison of atmospheric aerosol climatologies over southwestern Spain derived from AERONET and MODIS. Remote Sens. Environ., 115, 12721284, doi:10.1016/j.rse.2011.01.011, 2011.

Cachorro, V. E. and de Frutos, A. M.: A revised study of the validity of the general Junge relationship at solar wavelengths: Application to vertical atmospheric aerosol layer studies, Atmos. Res., 39, 113-126, 1995.

Cachorro, V. E., Vergaz, R., and de Frutos, A. M. A quantitative comparison of alpha Ångström turbidity parameter retrieved in different spectral ranges based on spectroradiometer solar radiation measurements, Atmos. Environ., 35, 5117-5124, 2001.

Cachorro, V. E., Toledano, C., Sorribas, M., Berjón, A., de Frutos A. M., and Laulainen, N.: An "in situ" calibration-correction procedure (KCICLO) based on AOD diurnal cycle: Comparative results between AERONET and reprocessed (KCICLO method) AOD-alpha data series 2000-2004 at El Arenosillo (Spain), J. Geophys. Res., 113, D02207. doi:10.1029/2007JD009001, 2008.

Dubovik, O. and King, M. D.: A flexible inversion algorithm for retrieval of aerosol optical properties from Sun and sky radiance measurements, J. Geophys. Res., 105, 20673-20696, 2000.

Dubovik, O., Smirnov, A., Holben, B., King, M. D., Kaufman, Y. J., Eck, T. F., and Slutsker, I. Accuracy assessments of aerosol optical properties retrieved from Aerosol Robotic Network (AERONET) Sun and sky radiance measurements, J. Geophys. Res., 105, 9791-9806, 2000.

Dubovik, O., Sinyuk, A., Lapyonak, T., Holben, B., Mishchenko, M., Yang, P., Eck, T., Volten, H., Muñoz, O., Veihelmann, B., van der Zande, J., Leon, J., Sorokin, M., and Slutsker, I.: Application of spheroid models to account for aerosol particle nonsphericity in remote sensing of desert dust. J. Geophys. Res., 111, D11208, doi:10.1029/2005JD006619, 2006. 
Eck, T. F., Holben, B. N., Reid, J. S., Dubovik, O., Smirnov, A., O'Neill, N. T., Slutsker, I., and Kinne, S.: Wavelengh dependence of the optical depth of biomass burning, urban, and desert dust aerosols. J. Geophys. Res., 104, 31333-31349, 1999.

Eck, T. F., Holben, B. N., Dubovik, O., Smirnov, A., Slutsker, I., Lobert, J. M., and Ramanathan, V. Column-integrated aerosol optical properties over the Maldives during the northeast monsoon for 1998-2000. J. Geophys. Res., 106, 28555-28566, doi:2001JD000786, 2001.

Eck, T. F., Holben, B. N., Dubovik, O., Smirnov, A., Goloub, P., Chen, H. B., Chatenet, B., Gomes, L., Zhang, X. Y., Tsay, S. C., Ji, Q., Giles, D., and Slutsker, I. Columnar aerosol optical properties at AERONET sites in central eastern Asia and aerosol transport to the tropical mid-Pacific, J. Geophys. Res., 110, D06202, doi:10.1029/2004JD005274, 2005.

Escudero, M., Castillo, S., Querol, X., Avila, A., Alarcon, M., Viana, M. M., Alastuey, A., Cuevas, E., and Rodriguez, S.: Wet and dry African dust episodes over eastern Spain, J. Geophys. Res., 110, D18S08, doi:10.1029/2004JD004731, 2005.

Gonzi, S., Baumgartner, D., and Putz, E.: Aerosol Climatology and Optical Properties of Key Aerosol Types Observed in Europe, IGAM/UG Technical Report for EU No. 1/2002 EDUCE, http: //www.uni-graz.at/en/igam1www_gonzi_educe_b.pdf, 2002.

Guerrero-Rascado, J. 1., Olmo, F. J., Avilés-Rodriguez, I., NavasGuzmán, F., Pérez-Ramírez, D., Lyamani, H., and AladosArboledas, L. Extreme Saharan dust event over the southern Iberian Peninsula in september 2007: active and passive remote sensing from surface and satellite, Atmos. Chem. Phys. 9, 84538469, doi:10.5194/acp-9-8453-2009, 2009.

Hansen, J. E. and Travis, L. D.: Light scattering in planetary atmospheres. Space Sci. Rev., 16, 527-610, doi:10.1007/BF00168069, 1974.

Hess, M., Koepke, P., and Schult, I.: Optical properties of aerosols and clouds: The software package OPAC, B. Am. Meteorol. Soc., 79, 831-844, 1998.

Holben, B., Eck, T. F., Slutsker, I., Tanré, D., Buis, J. P., Setzer, P., Vermote, E., Reagan, J. A., Kaufman, Y. J., Nakajima, T., Lavenu, F., Jankowiak, I., and Smirnov, A.: AERONET- A Federated Instrument Network and Data Archive for Aerosol Characterization, Rem. Sens. Environ., 66, 1-16, 1998.

Holben, B., Eck, T. F., Slutsker, I., Smirnov, A., Sinyuk, A., Schafer, J., Giles, D., and Dubovik, O.: AERONET's Version 2.0 quality assurance criteria. AERONET Technical and Quality Assurance Documents, 2006.

IPCC-Report 2007. Solomon, S., Qin, D., Manning, M., Chen, Z., Marquies, M., Averyt, K. B., Tignor, M., and Miller, H. L. (eds.): Cambridge University Press, Cambridge, New York, USA, Chapter 2.4, 2007.

Junge, C. E.: Air Chemistry and Radioactivity, Academic Press, New York, USA, 165-176, 1963.

Nakajima, T., Tonna, G., Rao, R., Boi, P., Kaufman, Y., and Holben, B.: Use of brightness measurements from ground for remote sensing of particulate polydispersions, Appl. Opt., 35, 26722686, 1996.

Olmo, F. J., Quirantes, A., Alcántara, A., Lyamani, H., and AladosArboledas, L.: Preliminary results of non-spherical aerosol method for the retrieval of the atmospheric aerosol optical properties. J. Quant. Spectrosc. Radiat. Transfer, 100, 305-314, doi:10.1016/j.jqsrt.2005.11.047, 2006.
Olmo, F. J., Quirantes, A., Lara, V., Lyamani, H., and AladosArboledas, L.: Aerosol optical properties assessed by an inversion method using the solar principal plane for non-spherical particles, J. Quant. Spectrosc. Radiat. Transfer, 109, 1504-1516, doi:10.1016/j.jqsrt.2007.12.019, 2008.

Ortiz de Galisteo, P., Análisis del contenido total en columna de vapor de agua atmosférico sobre la Península Ibérica medido con distintas técnicas: radiosondeos, fotómetros solares, y sistema GPS, PhD Thesis, Valladolid University, Valladolid, Spain, 2011.

O’Neil, N. T., Eck, T. F., Holben, B. N., Smirnov, A., and Dubovik, O.: Bimodal size distribution influences on the variation of Angstrom derivatives in spectral and optical depth space. J. Geophys. Res., 106, 9787-9806, 2001.

Prats, N., Cachorro, V. E., Sorribas, M., Mogo, S., Berjón, A., Toledano, C., de Frutos, A. M., de la Rosa, J., Laulainen, N., and de la Morena, B. A.: Columnar aerosol optical properties during "El Arenosillo 2004 summer campaign", Atmos. Environ., 42, 2643-2653, doi:10.1016/j.atmosenv.2007.07.041, 2008.

Prats, N.: Utilización del fotómetro Cimel (AERONET) para el análisis de parámetros microfísicos y radiativos del aerosol atmosférico en el suroeste de la Península Ibérica, PhD Thesis, Valladolid University, Valladolid, Spain, 2009.

Schuster, G. L., Dubovik, O., and Holben, B. N.: Angstrom exponent and bimodal aerosol size distribution. J. Geophys. Res., 111, D07207, doi:10.1029/2005JD006328, 2006.

Shifrin, K. S.: Simple relationships for the Ångström parameter of disperse systems, Appl. Opt., 34, 4480-4485, 1995.

Smirnov, A., Holben, B. N., Eck, T. F., Dubovik, O., and Slutsker, I.: Cloud-screening and Quality Control Algorithms for the AERONET Database, Remote Sens. Environ., 73, 337-349, 2000.

Sorribas, M.: Medida y caracterización del aerosol atmosférico en un ambiente rural y costero del suroeste de Europa. La distribución numérica de tamaños en el rango sub-micrométrico, PhD Thesis, Valladolid University, Valladolid, Spain, 2008.

Toledano, C., Cachorro, V. E., Berjón, A., de Frutos, A. M., Sorribas, M., de la Morena, B. A., and Goloub, P.: Aerosol optical depth and Ångström exponent climatology at El Arenosillo AERONET site (Huelva, Spain), Q. J. Roy. Meteorol. Soc., 133, 795-807, 2007a.

Toledano, C., Cachorro, V. E., de Frutos, A. M., Sorribas, M., Prats, N., and de la Morena, B. A. Inventory of African desert dust events over the southwestern Iberian Peninsula in 20002005 with an AERONET sunphotometer, J. Geophys. Res., 112, D21201. doi:10.1029/2006JD008307, 2007b.

Toledano, C., Cachorro, V. E., de Frutos, A. M., Torres, B., Berjón, A., Sorribas, M., and Stone, R. S.: Air masses classification and analysis of aerosol types at El Arenosillo (Spain), J. App. Meteor. Climat., 48, 962-981, 2009.

Vergaz, R., Cachorro, V. E., de Frutos, A. M., Vilaplana, J. M., and de la Morena, B.: Columnar characteristics of aerosols in the maritime area of the Cádiz Gulf (Spain). Int. J. Climat., 25, 1781-1804, doi:101002/joc.1208, 2005.

Waggoner, A. P., Weiss, R., Ahlquist, N., Covert, D., Will, S., and Charlson, R.: Optical characteristics of atmospheric aerosols, Atmos. Environ., 15, 1891-1909, 1981. 
Wendisch, M. and Von Hoyningen-Huene, W.: Possibility of refractive index determination of atmospheric aerosol particles by ground-based solar extinction and scattering measurements, Atmos. Environ., 28, 785-792, 1994. 